\title{
Physical Modeling of Flow Over an Axisymmetric Knoll Under Neutral Atmospheric Conditions
}

W. C. Cliff

J. D. Smith

February 1980

Prepared for the U.S. Department of Energy under Contract EY-76-C-06-1830

Pacific Northwest Laboratory Operated for the U.S. Department of Energy by Battelle Memorial Institute 
NOTICE

This report was prepared as an account of work sponsored by the United States Covernment. Neither the United States nor the Department of Energy, nor any of their employees, nor any of their contractors, subcontractors, or their employees, makes any warranty, express or implied, or assumes any legal liability or responsibility for the accuracy, completeness or usefulness of any information, apparatus, product or process disclosed, or represents that its use would not infringe privately owned rights.

The views, opinions and conclusions contained in this report are those of the contractor and do not necessarily represent those of the United States Government or the United States Department of Energy.

\author{
PACIFIC NORTHWEST LABORATORY \\ operated by \\ BATTELLE \\ for the \\ UNITED STATES DEPARTMENT OF ENERGY \\ Under Contract EY-76-C-06-1830
}
Printed in the United States of America Available from
National Technical Information Service United States Department of Commerce 5285 Port Royal Road Springfield, Virginia 22151

Price: Printed Copy 5 $\therefore$ Microfiche $\$ 3.00$

NTIS

-Pages Selling Price

$001-025$

026-050

$051-075$

076-100

101-125

$126-150$

$151-175$

$176-200$

$201-225$

$226-250$

$251-275$

D $76-300$

$$
\begin{array}{r}
\$ 4.00 \\
\$ 4.50 \\
\$ 5.25 \\
\$ 6.00 \\
56.50 \\
57.25 \\
58.00 \\
59.00 \\
59.25 \\
59.50 \\
510.75 \\
511.00
\end{array}
$$


PHYSICAL MODELING OF FLOW OVER AN AXISYMMETRIC KNOLL UNDER

NEUTRAL ATMOSPHERIC CONDITIONS

W. C. Cliff

J. D. Smith

February 1980

Prepared for

the U.S. Department of Energy under Contract EY-76-C-06-1830

Pacific Northwest Laboratory Richland, Washington 99352 
$\checkmark$ 


\section{ACKNOWLEDGMENTS}

The authors wish to express their gratitude to the program's technical monitor, Dr. Ari Patrinos of Oak Ridge National Laboratory and to

Drs. Harry Moses and Alan Rubin of the Department of Energy for their support. 


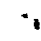

1

. 


\section{SUMMARY}

The Pacific Northwest Laboratory used a glass-walled hydraulic (water) flume to physically model air flow near an axisymmetric knoll in a neutral atmospheric boundary layer. The knoll was a 1:250 scale model. An upstream velocity profile ( $1 / 7$ power law), characteristic of a neutral atmospheric boundary layer, was produced by locating a 10-cm-high (4-in.) trip near the flume entrance and by appropriately roughening the flume floor.

Mean velocity, rms velocity, and turbulence intensity profiles were measured at locations near the knoll using an existing laser Doppler anemometer system. The flow accelerated over the knoll and produced a relatively uniform velocity profile at the crest. The measured velocity profile was in close agreement with a theoretical velocity profile developed using potential flow theory and an upstream power law velocity profile. The turbulence intensity decreased at the crest of the knoll as a result of the flow acceleration. 


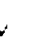




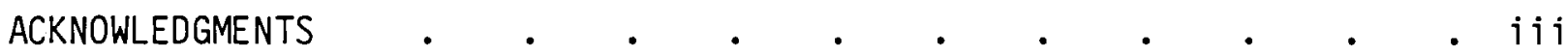

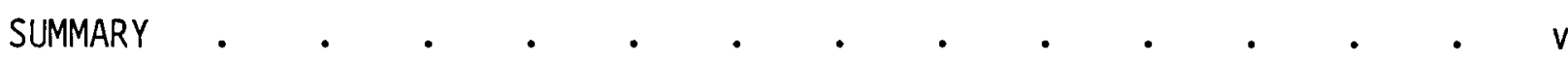

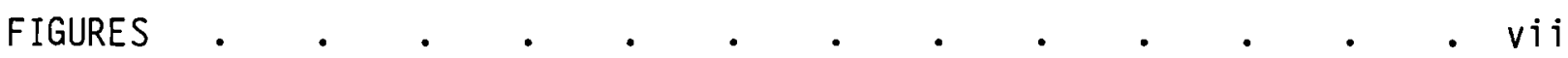

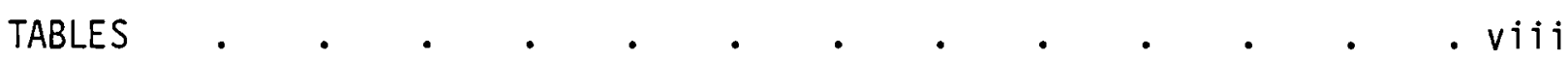

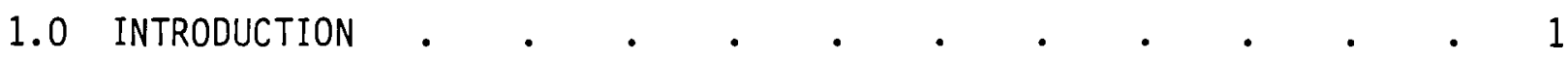

2.0 CONCLUSIONS AND RECOMMENDATIONS $\quad \cdot \quad \cdot \quad \cdot \quad \cdot \quad \cdot \quad \cdot \quad \cdot 3$

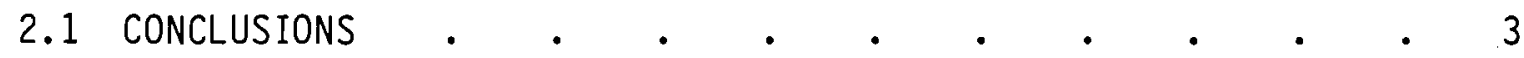

2.2 RECOMMENDATIONS $. \quad . \quad . \quad . \quad . \quad . \quad . \quad . \quad . \quad . \quad 3$

3.0 ATMOSPHERIC BOUNDARY LAYER MODELING REQUIREMENTS . . . . 5

4.0 THEORETICAL VELOCITY PROFILES ABOVE THE CREST

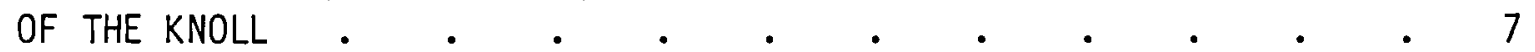

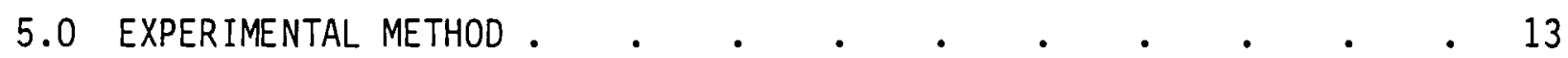

5.1 EXPERIMENTAL FACILITIES AND EQUIPMENT • • • • . . 13

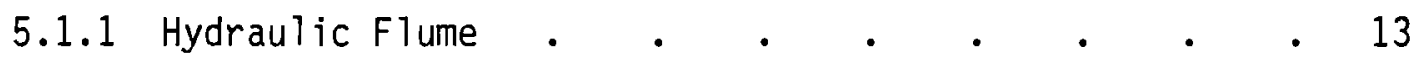

5.1 .2 Model Knoll Design . . . . . . . . . 14

5.1 .3 Laser Doppler Anemometer . . . . . . . 14

5.1.4 Data Acquisition System . . . . . . . . 16

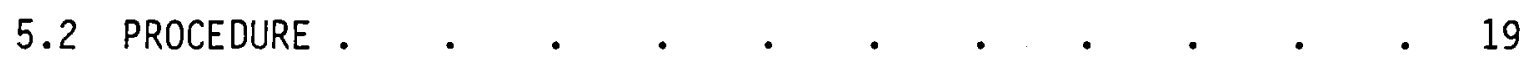

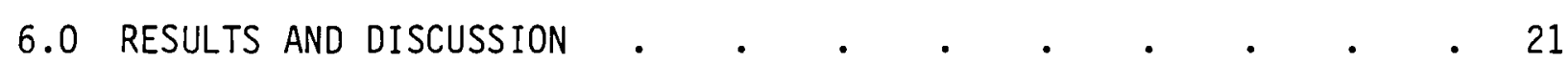

7.0 ERROR AND UNCERTAINTY ANALYSIS . . . . . . . . . 27

REFERENCES . . . . . . . . . . . . . . 29

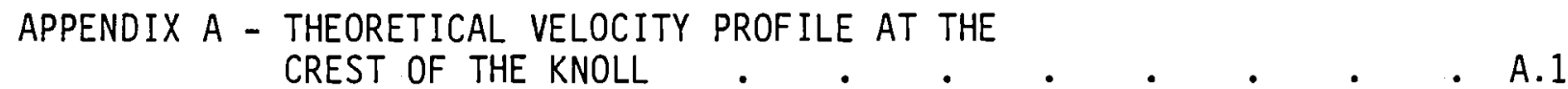

APPENDIX B - UNCERTAINTY ANALYSIS . . . . . . . . . . B.1 


\section{FIGURES}

1 Theoretical Velocity Profile Over the Crest

of the Knoll . . . . . . . . . . . . 10

2 Hydraulic Flume Facility. . . . . . . . . . . 13

3 Laser Doppler Anemometer System . . . . . . . . 15

4 Laser Doppler Anemometer Signal Processing System . . . . 16

5 Laser Doppler Anemometer System and Flume Facility • • • 17

6 Data Acquisition System . . . . . . . . . . . 18

7 Measured Upstream Velocity Profile . . . . . . . 22

8 Nondimensional Velocity Profiles . . . . . . . . 23

9 Turbulence Intensity Profiles. . . . . . . . . 25

\section{TABLES}

1 Expected Velocity Profile Above the Crest of an Axisymmetric Knoll with a 1/7 Power Law Approach Velocity Profile . . . . . . . • . . 11

2 Nondimensional Velocity Profiles Measured Over the Knoll • • . . . . . . . . . . 24 
PHYSICAL MODELING OF FLOW OVER AN AXISYMMETRIC

KNOLL UNDER NEUTRAL ATMOSPHERIC CONDITIONS

\subsection{INTRODUCTION}

Developing methods to estimate the trajectory and diffusion of thermal plume releases from power generation facilities has been the prime objective of the Meter program (Meteorological Effects of Thermal Energy Releases) sponsored by the Department of Energy. The Pacific Northwest Laboratory (PNL) was contracted to perform a physical simulation of flow near an axisymmetric knoll with the long-range objective of modeling the trajectory of exhaust plumes from mechanical draft cooling towers in complex terrain. The objectives of this initial study were to: 1) modify an existing water flume system to permit simulation of a neutral atmospheric boundary layer, 2) utilize an existing laser Doppler anemometer (LDA) system to measure fluid velocities and turbulence intensities, and 3) characterize the fluid flow near an axisymmetric knoll subjected to a neutral atmospheric boundary layer.

Characteristics of an atmospheric surface layer (the lower portion of the atmospheric boundary layer) that has developed over a flat, homogeneous terrain are well understood because of extensive measurements in the lowest $150 \mathrm{~m}$ $(493 \mathrm{ft})$ of the atmosphere. G. I. Taylor ${ }^{(1)}$ began quantifying atmospheric surface layer characteristics in a study in 1913, when he observed the motion of a tethered balloon. Since that time, investigators have performed many measurements which have aided in describing the atmospheric surface layer. In recent years, excellent compilations and reviews have been presented $(2,3,4)$ with the neutral atmospheric boundary layer receiving comprehensive evaluations.

However, the characterization of atmospheric flow over complex terrain has not been well established, partly because few field test programs have large enough measurement networks. Because the expense of such programs is prohibitively large, most flow characterizations are performed by simulating the desired flow field. There are two basic approaches to simulation: 
physical modeling and numerical modeling. Physical modeling in fluid channels has a great flexibility in simulating the complex terrain and the atmospheric boundary layer. $(5,6)$ The state of the art in numerical modeling does not permit characterization of flow over nonhomogeneous surface roughnesses and complex terrain. (7)

Physical modeling of atmospheric flows over complex terrain has primarily been considered for stably stratified flows. $(8,9,10)$ For stably stratified cases, no boundary layer is used, and the approaching flow has a uniform velocity distribution. Characterization of flow over complex terrain under neutral conditions is more limited. (9) The effort of Hunt, Snyder, and Lawson characterized the flow over a large hill when the crest of the hill was near or above the height of the atmospheric boundary layer. (9) The present PNL study used the same model shape as that used by Hunt, Snyder, and Lawson but scaled the model to simulate a knoll height of approximately $19 \mathrm{~m}(62.5 \mathrm{ft})$, which corresponds to the height of many mechanical draft cooling towers. This study measures the mean velocity, rms velocity, and turbulence intensity profiles near and above the modeled knoll. A theoretical mean velocity profile is also developed and compared to the measured mean velocity profile. 


\subsection{CONCLUSIONS AND RECOMMENDATIONS}

The following conclusions and recommendations are based upon the results of the analysis and experimental testing performed during this study.

\subsection{CONCLUSIONS}

- Physical modeling in the PNL flume was used to successfully characterize the fluid flow near an axisymmetric knoll under neutral atmospheric conditions.

- The LDA provided a satisfactory method of obtaining velocity and turbulence intensity profiles near the model knoll.

- Measured mean velocity profiles were found to be fairly uniform above the crest of the model knoll and were in good agreement with a theoretical profile developed from potential flow theory.

- The turbulence intensity decreased at the crest of the knoll as a result of flow acceleration.

\subsection{RECOMMENDATIONS}

- An extension of this effort should be performed to investigate the effects of a local surface protuberance, such as an axisymmetric knoll, on mechanical draft cooling tower plumes under neutral atmospheric conditions.

- Future studies should characterize fluid flow over other generic topographic shapes. 


\subsection{ATMOSPHERIC BOUNDARY LAYER MODELING REQUIREMENTS}

Physical modeling of the atmospheric boundary layer requires geometric, dynamic, and thermic similarity between model and prototype. Determination of the nondimensional parameters required to ensure similarity between model and prototype can be obtained by inspectional analysis of the governing equations for mass, momentum, and energy. Cermak ${ }^{(6)}$ has performed an inspectional analysis, showing that exact similarity requires the model and prototype to be equal in

1) Rossby number

2) Richardson number

3) Reynolds number

4) Prandt 1 number

5) Eckert number

and have consistent geometric scaling in all dimensions.

The approach flow and surface boundary conditions require similarity of

1) mean and turbulent velocity profiles

2) temperature profiles and distribution

3) pressure gradient (should be zero)

4) surface roughness

5) topography.

All of the above requirements cannot be met because of physical modeling limitations. A particular experiment must therefore be designed to accurately simulate those scales of motion which are of greatest significance to the specific application. The similarity requirements are substantially reduced for the case considered in this study, but similarity of the following nondimensional parameters was important.

1) geometric scale

2) Richardson number

3) Reynolds number

4) mean and turbulent velocity profile

5) pressure gradient 
6) surface roughness

7) topography.

This study provided similarity for the seven parameters listed above as follows:

1) Geometric surface roughness lengths were scaled 1:250.

2) Richardson numbers for both the neutral atmosphere and the model were equal to zero.

3) Reynolds number similarity was not met. This did not significantly limit modeling because the significant flow characteristics were weakly dependent upon the Reynolds number. ${ }^{(6)}$

4) Similarity for the mean and turbulent velocity profiles were attained by tripping the boundary layer and roughening the surface upstream of the mode 1 knoll until the boundary layer velocity profiles were similar to the desired atmospheric velocity profiles.

5) Pressure gradients in both the model and the neutral atmosphere were equal to zero.

6) Surface roughness was aerodynamically similar when the velocity profiles were made similar.

7) Topography was scaled at 1:250, to provide geometric similarity between model and prototype.

The following similarity parameters were not important:

1) Rossby number similarity is only required to simulate larger scales of motion.

2) Prandt 1 number was not important because an adiabatic mode 1 was considered.

3) Eckert number corresponds to the Mach number squared. In an order of magnitude analysis, the Eckert number was found to be 
very small compared to unity for both the model and the atmospheric conditions. Thus, the term in the governing energy equation in which the Eckert number appears was also small compared to other terms. 

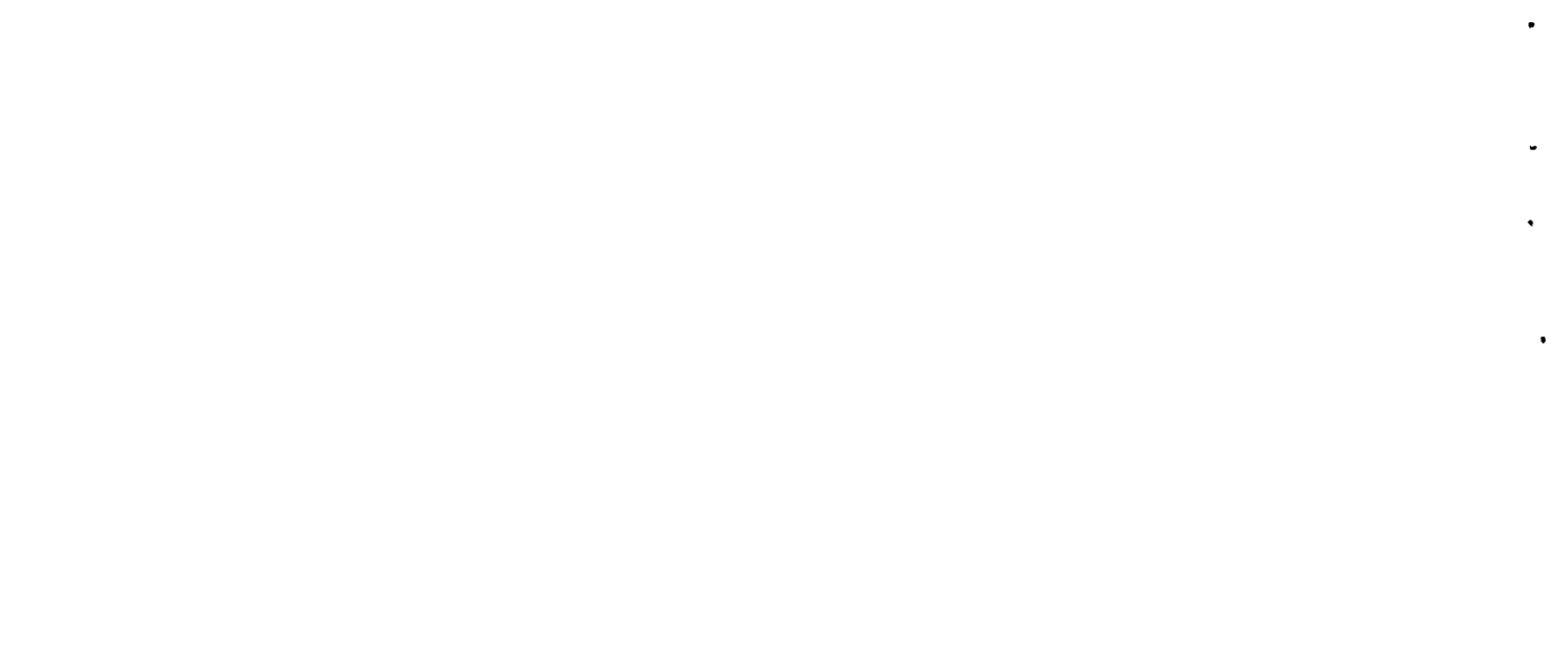


\subsection{THEORETICAL VELOCITY PROFILE ABOVE THE CREST OF A KNOLL}

One can estimate the velocity profile expected above the top of an axisymmetric knoll using potential flow theory for flow near a half sphere and adjusting the approach velocities to be consistent with the upstream velocity profile. This replaces the uniform upstream velocity profile conventionally assumed in potential flow theory. A detailed analysis presented in Appendix $A$ resulted in the following relationship for the expected velocity profile above the centerline of an axisymmetric knoll.

$$
U_{c k}=U_{u s, Z=r_{0}}\left(x^{2}-\frac{1}{x}\right)^{n / 2}\left(1+\frac{1}{2 x^{3}}\right)
$$

where: $U_{c k}=$ velocity at the crest of the knoll

$U_{u s}=$ upstream velocity

$Z$ = upstream height

$r=$ the vertical distance from the center of the knoll

$\mathrm{n}=$ exponent of power law for approach velocity

$r_{0}=$ the height of knoll

$\begin{aligned} \frac{U_{1}}{U_{2}} & =\left(\frac{Z_{1}}{Z_{2}}\right)^{n}, n=1 / 7 \text { for the conditions presented in this study) } \\ X & =r / r_{0} .\end{aligned}$

Using Equation 1, a profile of the expected mean velocity at the crest of a knoll with a $1 / 7$ power law approach velocity profile is presented in Figure 1. The greatest acceleration of the upstream flow occurs near the surface, which results in an almost vertical velocity profile above the centerline of the knoll. At $r=r_{0}$, the mean velocity goes to zero, which is consistent with the required no-slip condition at the surface. Table 1 presents specific values of the mean velocities presented in Figure 1 . These values show the small change in elevation required to reach a mean velocity equivalent to the mean velocity observed upstream at a height equal to the height of the knoll. 


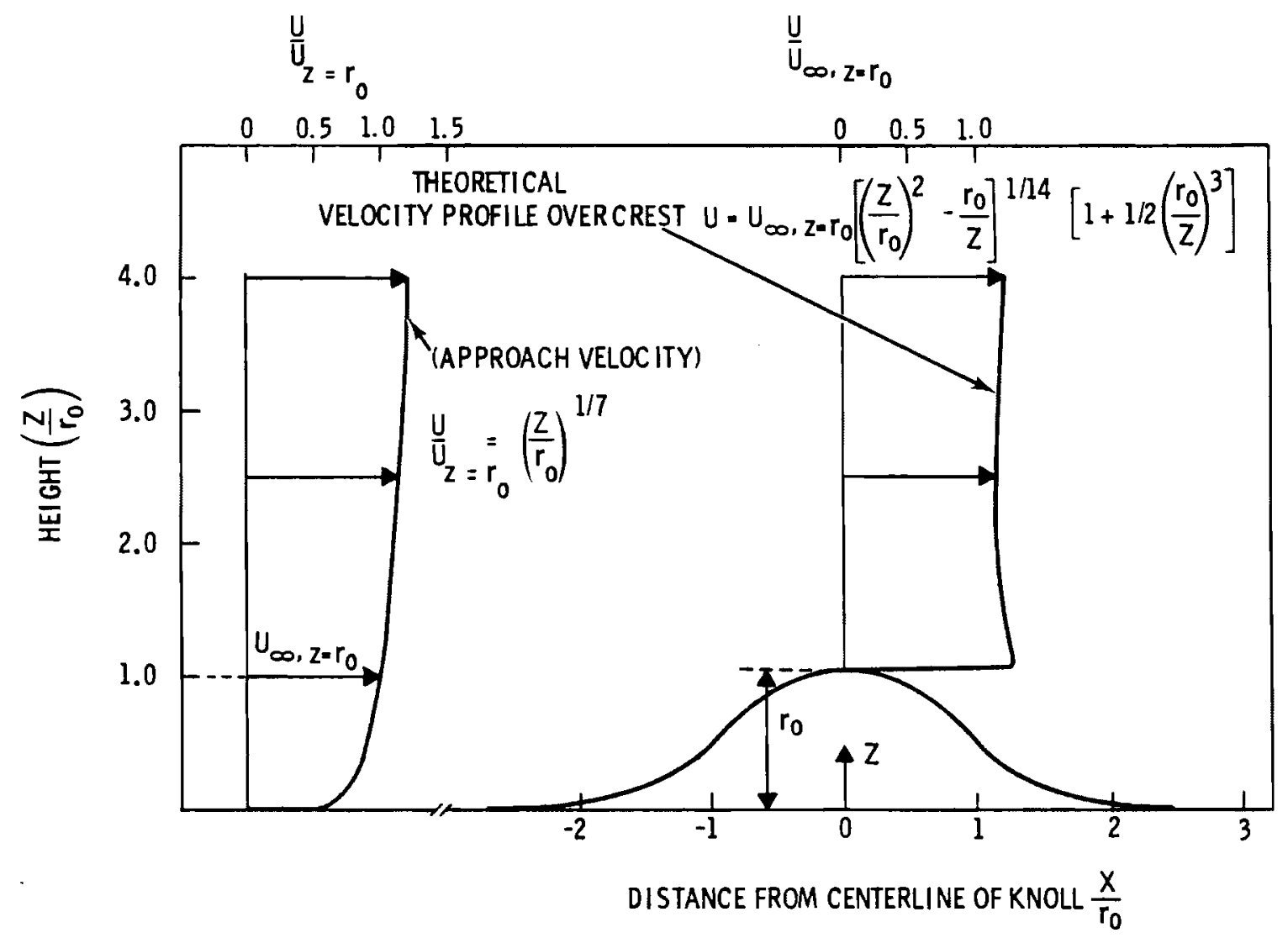

FIGURE 1. Theoretical Velocity Profile Over the Crest of the Knoll 
TABLE 1. Expected Velocity Profile Above the Crest of an Axisymmetric Knoll with a 1/7 Power Law Approach Velocity Profile

\begin{tabular}{|c|c|}
\hline$x=\frac{r}{r_{0}}$ & $\frac{U}{U U S, z=r_{0}}$ \\
\hline $\begin{array}{l}1.00 \\
1.00001 \\
1.0001 \\
1.001 \\
1.005 \\
1.01 \\
1.05 \\
1.10 \\
1.20 \\
1.30 \\
1.40 \\
1.50 \\
1.60 \\
1.70 \\
1.80 \\
1.90 \\
2.00 \\
2.25 \\
2.50 \\
2.75 \\
3.00 \\
3.50 \\
4.00 \\
5.00\end{array}$ & $\begin{array}{l}0.00 \\
0.71 \\
0.84 \\
0.99 \\
1.11 \\
1.16 \\
1.25 \\
1.26 \\
1.24 \\
1.22 \\
1.20 \\
1.19 \\
1.18 \\
1.17 \\
1.17 \\
1.16 \\
1.16 \\
1.16 \\
1.17 \\
1.18 \\
1.19 \\
1.21 \\
1.23 \\
1.26\end{array}$ \\
\hline
\end{tabular}





\subsection{EXPERIMENTAL METHOD}

This section describes the experimental facilities, measuring equipment, and the procedure used in modeling atmospheric flow over a knoll under neutral flow conditions.

\subsection{EXPERIMENTAL FACILITIES AND EQUIPMENT}

This section presents discussions of the hydraulic flume, the model knoll, the laser Doppler anemometer, and the data acquisition system used to obtain local velocity and turbulence intensity data.

\subsubsection{Hydraul ic Flume}

An existing PNL hydraulic flume used for this study contains glass walls with an open channel flow section $1.2 \mathrm{~m}(4 \mathrm{ft})$ wide, $1.5 \mathrm{~m}(5 \mathrm{ft})$ deep and $12.2 \mathrm{~m}(40 \mathrm{ft})$ long as shown in Figure 2. The recirculating flume has a maximum flowrate capability of $0.28 \mathrm{~m}^{3} / \mathrm{s}\left(10 \mathrm{ft}^{3} / \mathrm{s}\right)$. Pump flow rates are measured with a calibrated orifice meter in the $25.4-\mathrm{cm}(10-i n$.$) return line.$

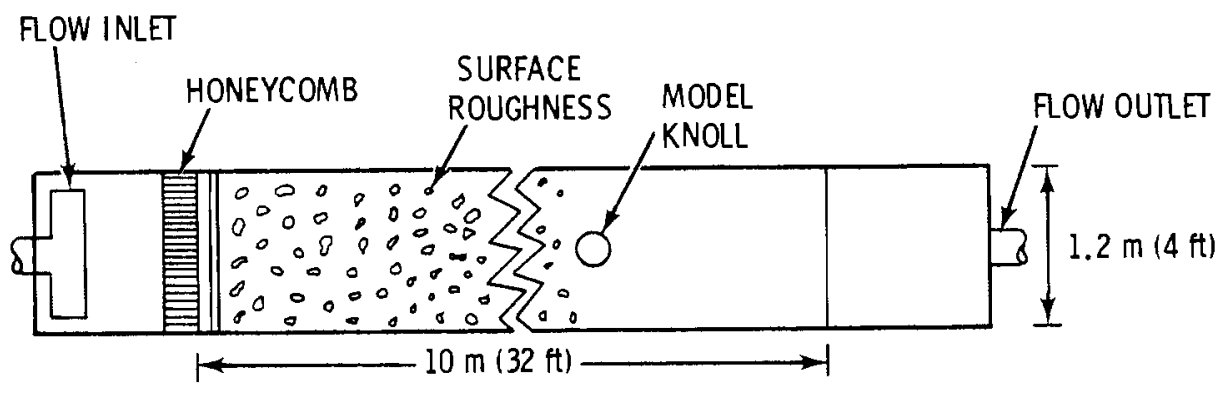

a) PLAN VIEW

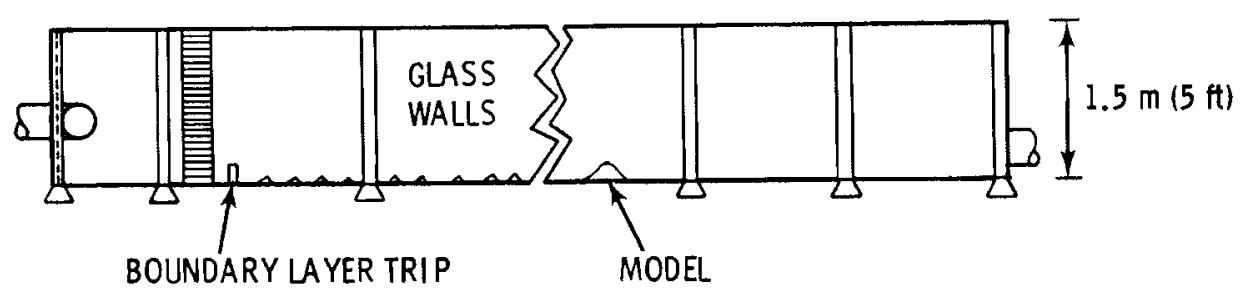

b) ELEVATI ON VIEW

FIGURE 2. Hydraulic Flume Facility 
After passing through a 1-m (38-in.) stilling chamber, the flow is slightly accelerated and then flows through a honeycomb flow straightener and turbulence suppressor which consists of $0.3-\mathrm{cm}$ (1/8-in.) diameter by 23-cm (9-in.) long flow channels. The total blockage created by the honeycomb is less than 2 percent of the available flow area. A 10-cm (4-in.) high boundary layer trip that extended across the width of the flume was installed approximately $10 \mathrm{~cm}$ (4 in.) downstream from the honeycomb. Crushed, 1.9-cm (3/4-in.) aggregate spaced randomly with a mean spacing of approximately $7.6 \mathrm{~cm}$ (3 in.) was located on the flume floor between the boundary layer trip and the model knoll. The model knoll was located $7 \mathrm{~m}(22 \mathrm{ft})$ downstream from the boundary layer trip. The boundary layer trip and the crushed aggregate produced a neutral boundary layer exhibiting a $1 / 7$ power law velocity profile upstream of the model knoll.

\subsubsection{Model Knoll Design}

The axisymmetric knoll shape chosen for this study is defined by the following formula:

$$
h=r_{0}\left(\frac{1}{1+\frac{r^{4}}{r_{0}}}\right)
$$

where $h$ equals the vertical height of the hill at a distance $r$ from the centerline, and $r_{0}$ is the centerline vertical height of the hill. This shape has been previously used by the Environmental Protection Agency ${ }^{(9)}$ and has gaussian-shaped features near the top of the hill but decays more rapidly at large values of $r$. The model used for this study was fabricated from a $7.5-\mathrm{cm}$ (2.94-in.) aluminum block with a radius of $20.3 \mathrm{~cm}$ ( 8 in.). Pea gravel having a diameter of approximately $0.5 \mathrm{~cm}$ (3/16 in.) was glued to the knoll to provide an aerodynamically rough surface for testing. At a scale of 1:250, the mode 1 represented a $19-\mathrm{m}(62.5-\mathrm{ft})$ knol1.

\subsubsection{Laser Doppler Anemometer}

A single-component laser Doppler anemometer (LDA) shown in Figure 3 was used to measure fluid velocities. The LDA measured the velocity in the fluid 


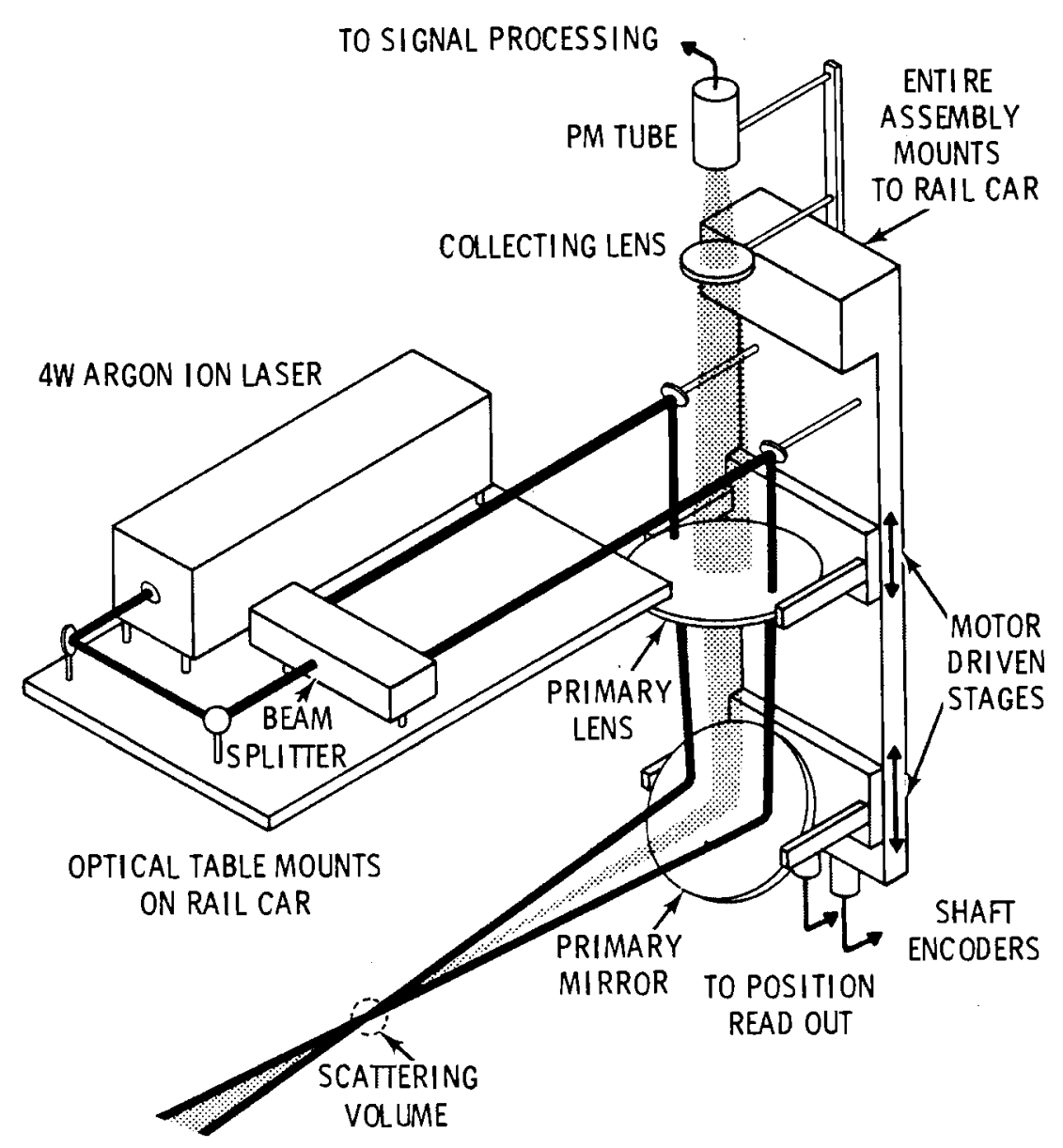

FIGURE 3. Laser Doppler Anemometer System

stream by determining the velocity shift in monochromatic light scattered by microscopic particles in the fluid. The laser beam from a 4-W argon-ion laser was split into two parallel beams and then focused through a system of mirrors and a lens to intersect within the flowing fluid. The sample volume formed at the intersection of the two beams was $1.6 \mathrm{~cm}(0.63$ in.) long and $0.07 \mathrm{~cm}$ (0.03 in.) in diameter. Light scattered from the sample volume was directed to a photomultiplier detector. The output signal from the detector was monitored by a Doppler signal processor. The processor provided a digital display of the Doppler frequency and an analog output voltage scaled to that frequency. The location of the sample volume was varied by movement of the lens and mirror, and was monitored by encoders coupled to their respective drive 
mechanisms. Resolution and control of the system was $0.16 \mathrm{~cm}(0.006$ in.) in any direction. The mean analog voltage from the processor and the output of the encoders were processed and stored by a mini-computer which was used to reduce, tabulate, and plot the flow field data. Figure 4 shows a schematic of the LDA signal processing system. Figure 5 shows the LDA system in operation.

\subsubsection{Data Acquisition System}

Analog and digital signals from the laser system output and the sample volume position were fed directly into a mini-computer data acquisition and control system which was dedicated to the hydraulic flume facility. The data acquisition and control system permitted processing and storage on 512 separate channels. The data were converted to engineering units and processed in final form within the computer system, and the graphical analys is of the data was displayed on a cathode ray tube (CRT) from which direct hard copies were made using an available commercial hard copier. Figure 6 is a schematic of the data acquisition system.

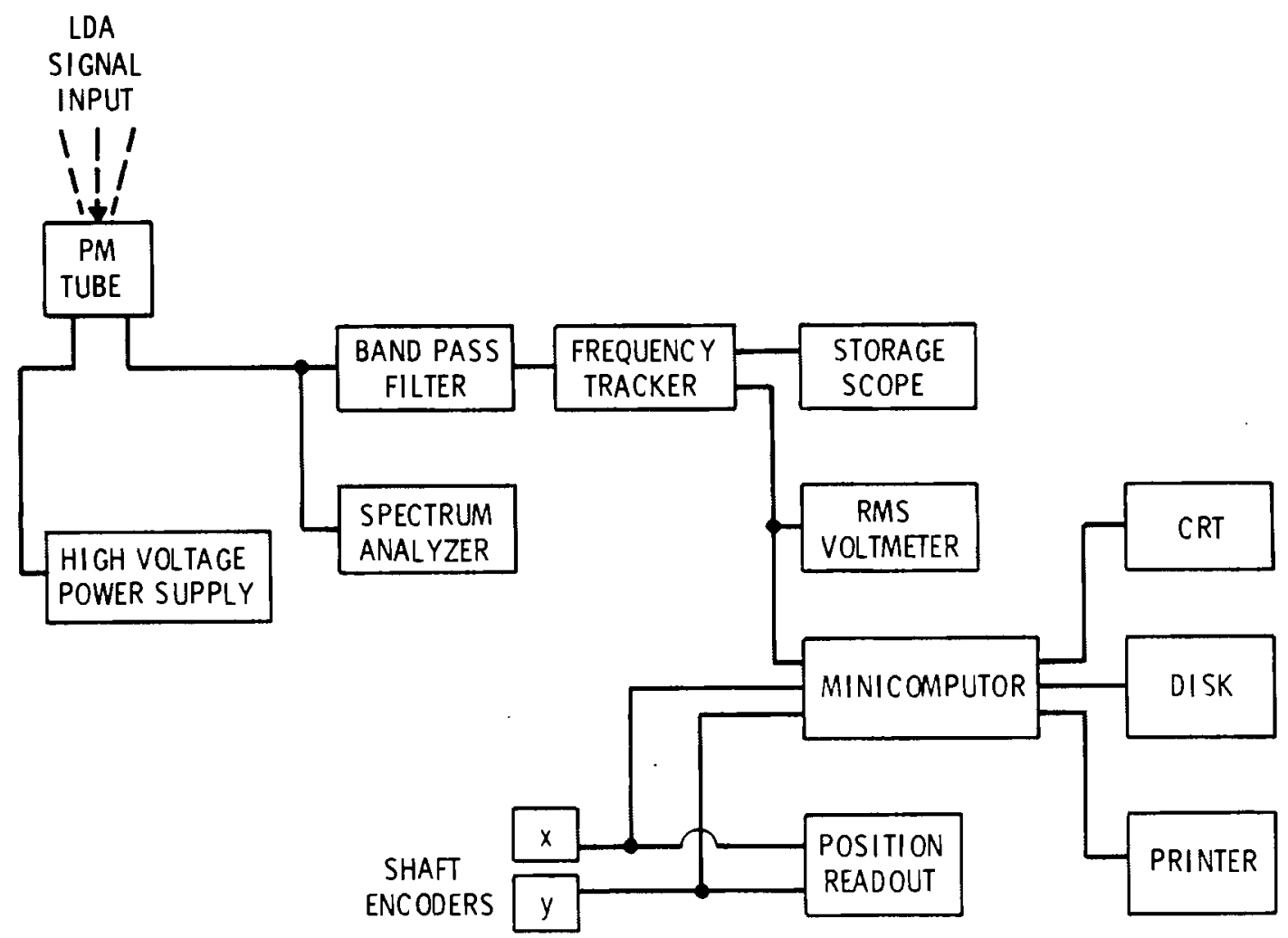

FIGURE 4. Laser Doppler Anemometer Signal Processing System 


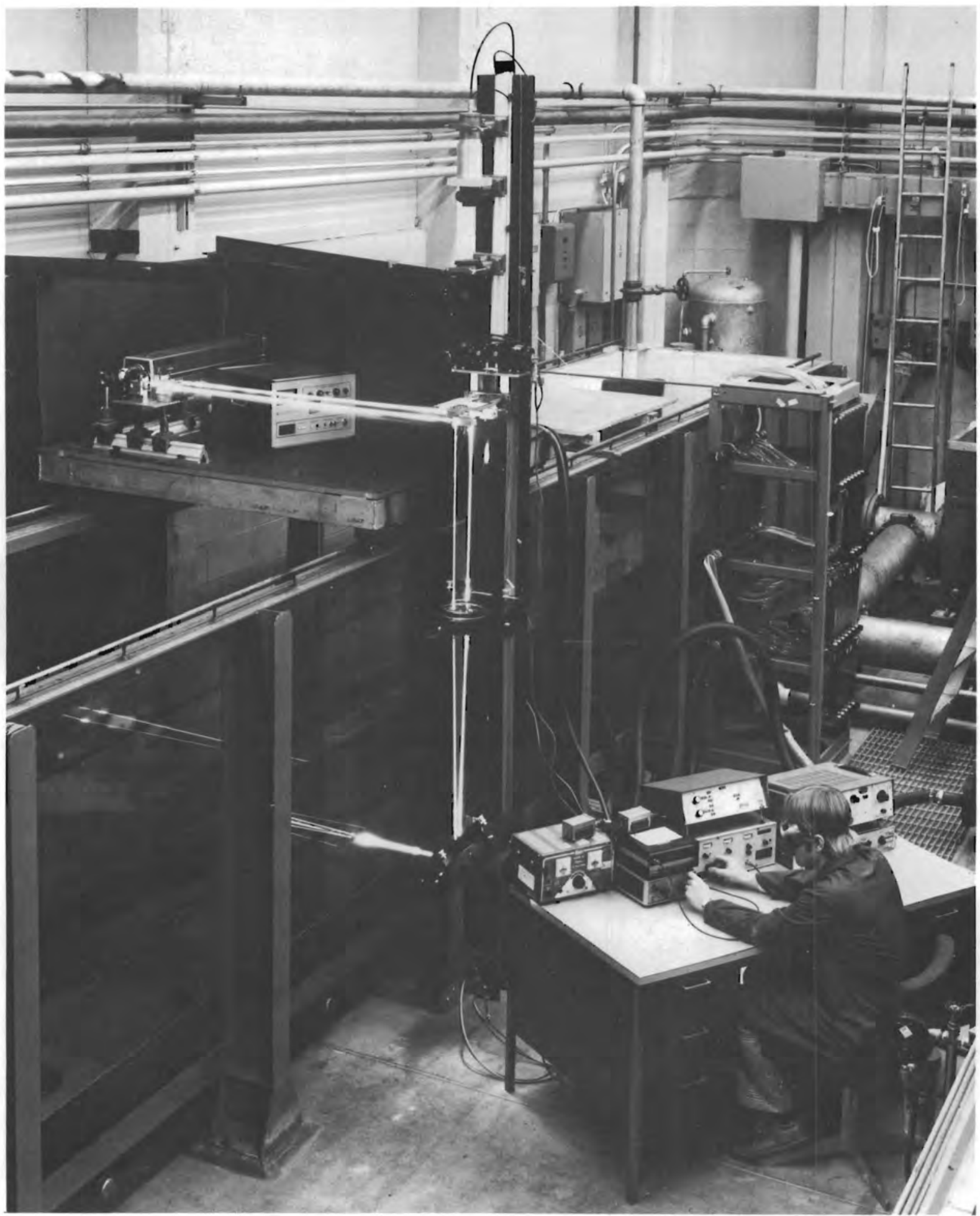

FIGURE 5. Laser Doppler Anemometer System and Flume Facility 
DATA ACQUISITI ON SYSTEM

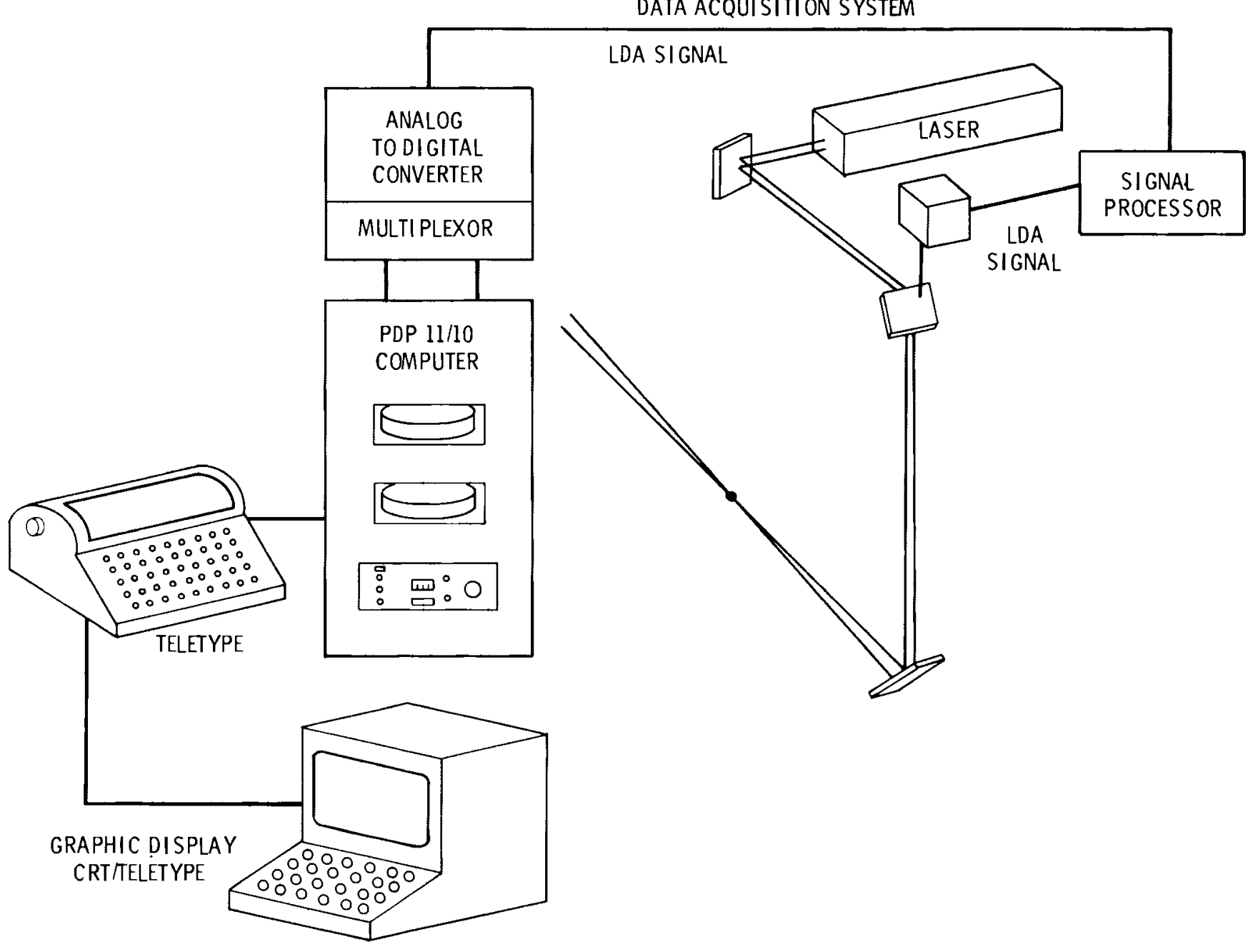

FIGURE 6. Data Acquisition System 


\subsection{PROCEDURE}

The hydraulic flume was filled with water to a height of approximately $1 \mathrm{~m}(3 \mathrm{ft})$ and left to stand for several days to remove entrained air resulting from the filling process. The water in the flume was then circulated while measurements of velocity were obtained using the LDA system. Lateral velocity profiles were obtained across the flow channel to ensure that the velocity profile was invariant with regard to lateral location. The longitudinal mean and turbulent velocity profiles were then obtained at locations $30.5 \mathrm{~cm}$ (12 in.), $15.2 \mathrm{~cm}$ (6 in.), $7.6 \mathrm{~cm}$ (3 in.) upstream and downstream of the knoll centerline as well as at the apex of the knoll. Velocity profiles were also obtained laterally from the knoll centerline at distances of $7.6 \mathrm{~cm}$ ( 3 in.) and $15.2 \mathrm{~cm}$ ( 6 in.). These lateral profiles could only be obtained at elevations greater than the height of the knoll due to a large specular reflection from the knoll surface at lower elevations. The specular light reflection as much greater than the intensity of the Doppler signal from the focal volume of the laser system. The specular reflection swamped the photodetection system and thus did not permit an evaluation of the Doppler signal.

The Doppler signal detected by the photodetector was fed to a commercial laser Doppler signal tracking system which produced an analog voltage output proportional to the fluid velocity. The mean analog output was sent to the computer where it was converted to a mean velocity. The instantaneous analog output was sent to a true rms meter whose output was sent to the computer and converted to the turbulence rms velocity. The location of a measurement was simultaneously fed to the computer from digital encoders which provided a signal proportional to the location of the laser optics. The data was then converted to engineering units, providing velocity profile information at each desired location. 



\subsection{RESULTS AND DISCUSSION}

A 1/7 power law velocity profile was established by using a 10-cm (4-in.) trip fence $6.7 \mathrm{~m}(22 \mathrm{ft})$ upstream of the knoll and by roughing the floor of the hydraulic flume using 1.9-cm (3/4-in.) crushed aggregate spaced approximately $7.6 \mathrm{~cm}$ ( 3 in.) apart. A plot of the measured upstream velocity profile obtained $30.5 \mathrm{~cm}$ (12 in.) upstream from the knoll is shown in Figure 7 . In this nondimensional plot of mean velocity, the region where the log profile fits the data corresponds to the constant shear stress layer in the atmospheric boundary layer. The shear, $U_{\star}$, for the case presented is $0.087 U_{Z=r_{0}}$.

Figure 8 provides plots of the mean velocity profile at various locations over the knoll. It is interesting to note how well the experimental velocity profile obtained above the knoll centerline agrees with the theoretical velocity profile developed in Section 4. Table 2 presents the values of all the velocity data. For a scale of 1 to 250 , the upstream velocity profile corresponds to an aerodynamic surface roughness of approximately $0.27 \mathrm{~m}(0.9 \mathrm{ft})$, which is consistent with a neutral atmospheric boundary layer developing over fairly level, sparsely wooded countryside. (4)

Figure 9 is a plot of the level of turbulence, $\sigma_{u}$, and turbulence intensity, $\sigma_{u} / U$, measured upstream and at the crest of the knoll. The constant value of the level of turbulence upstream may be interpreted as representing the constant shear portion of the boundary layer, which may extend to approximately $100 \mathrm{~m}$ (328 ft) in the atmosphere. That is, for the neutral boundary layer, $\sigma_{u}$ is proportional to $U_{\star}{ }^{(12)}$, shear velocity, which is equal to $\sqrt{\tau / \rho}$ where $\tau$ is the local shear stress and $\rho$ is the fluid density. Thus, $\tau$ is proportional to $\sigma_{u}{ }^{2}$, and if $\sigma_{u}$ is constant, the shear stress is constant.

It is also interesting to note that the level of turbulence does not change significantly as the bulk flow is accelerated over the knoll. This was expected because it is generally accepted that when flow is accelerated, the longitudinal turbulence level will stay constant or decrease. Some of the longitudinal kinetic energy will be transferred to the lateral and/or vertical components of flow. 


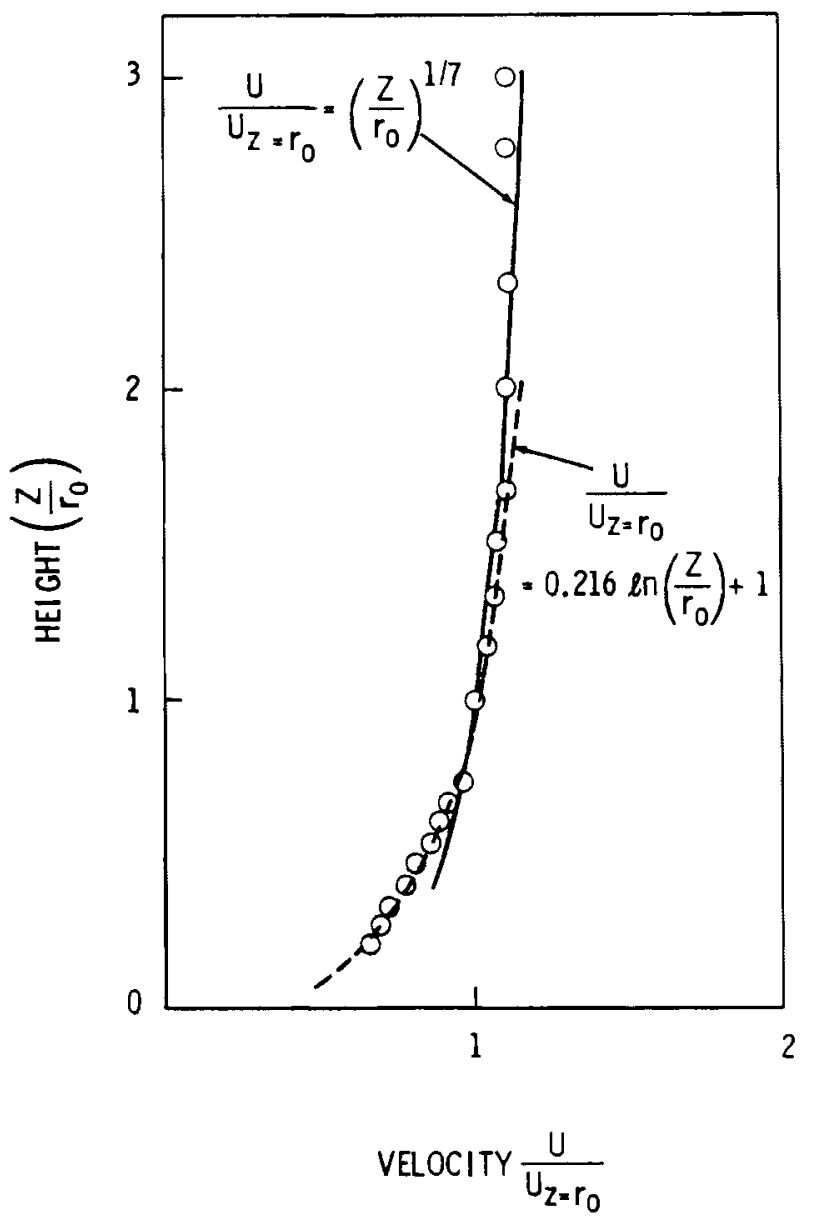

FIGURE 7. Measured Upstream Velocity Profile

As with the theoretical velocity profile developed in Section 4.0 , the nondimensional velocity profile measurements presented in Figures 7,8 , and 9 and Table 2 apply independently of scaling to any geometrically similar knoll which is submerged in a fluid with an approach velocity profile similar to that developed upstream of the model knoll; i.e., the test results are applicable for any scaling, not just the 1:250 scaling for which this test was intended. 


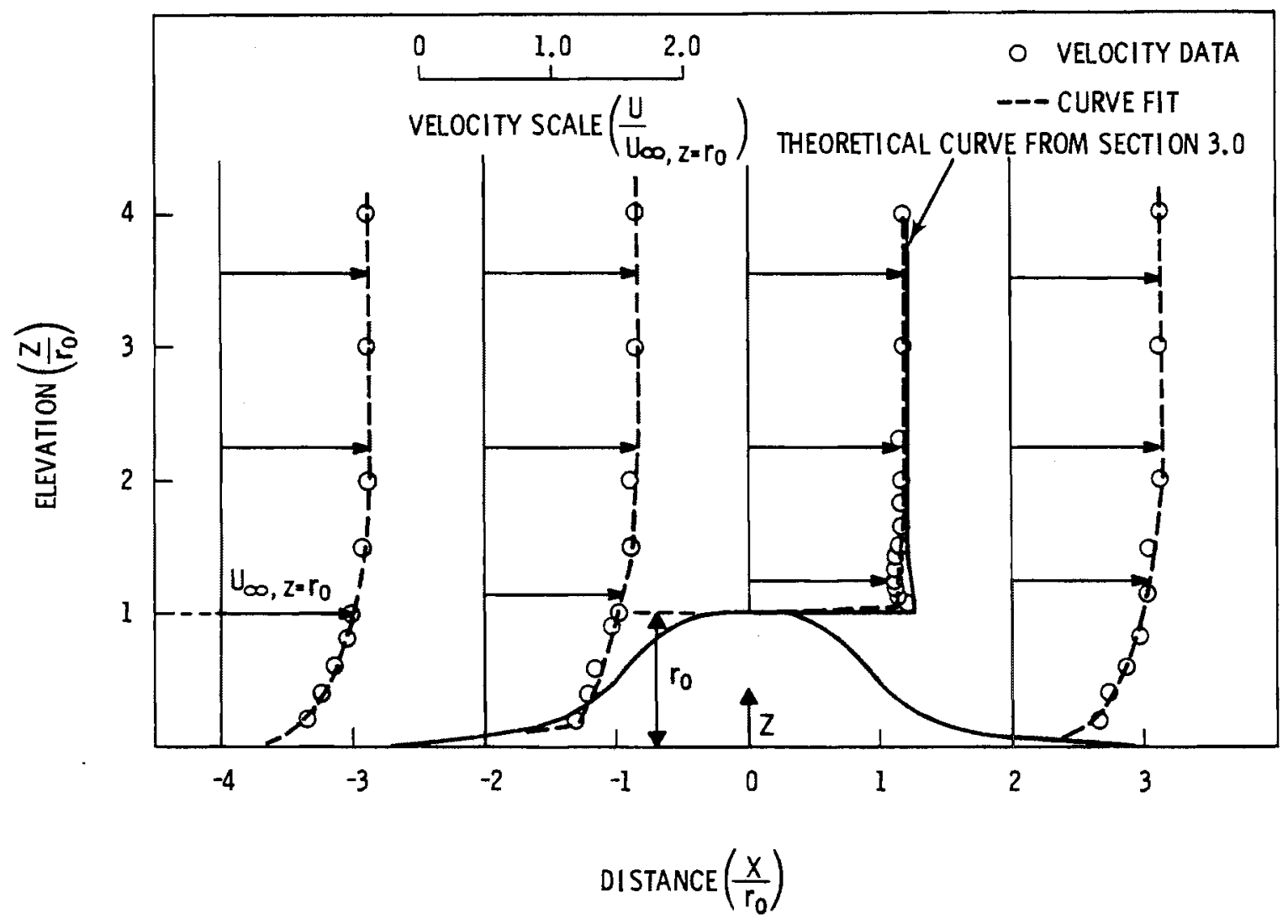

FIGURE 8. Nondimensional Velocity Profiles $\left(U / U_{Z}=r_{0}, X=-30.5 \mathrm{~cm}\right)$ 
TABLE 2. Nondimensional Velocity Profiles
Over the Knoll at Six Locations $(a)\left(\frac{U}{U}\right.$ and $\left.\frac{\sigma u}{U}\right)$ Measured

\begin{tabular}{|c|c|c|c|c|c|c|c|c|}
\hline \multirow{3}{*}{ (Z) } & \multirow{3}{*}{$\frac{\overline{X / r_{0}}=-4}{\frac{U}{U^{\prime}}}$} & \multirow{3}{*}{$\frac{X / r_{0}=-2}{\frac{U}{U^{\prime}}}$} & \multirow{3}{*}{$\frac{x / r_{0}=-1}{\frac{U}{U^{\prime}}}$} & \multirow{3}{*}{$\frac{\text { Location }}{\frac{\text { Knol1 }}{\frac{U}{U^{1}}}}$} & \multirow{2}{*}{\multicolumn{2}{|c|}{$x / r_{0}=1$}} & \multirow{2}{*}{\multicolumn{2}{|c|}{$x / r_{0}=2$}} \\
\hline & & & & & & & & \\
\hline & & & & & $\frac{U}{U^{\prime}}$ & $\frac{\sigma_{u}}{U}$ & $\frac{U}{U^{\prime}}$ & $\frac{\sigma_{u}}{U}$ \\
\hline \multicolumn{9}{|c|}{$\begin{array}{l}0.0667 \\
0.133\end{array}$} \\
\hline $\begin{array}{l}0.200 \\
0.267\end{array}$ & $\begin{array}{l}0.570 \\
0.700\end{array}$ & $\begin{array}{l}0.682 \\
0.691\end{array}$ & & & & & $\begin{array}{l}0.666 \\
0.727\end{array}$ & $\begin{array}{l}0.085 \\
0.078\end{array}$ \\
\hline 0.333 & 0.723 & 0.727 & & & & & 0.799 & 0.071 \\
\hline 0.400 & 0.780 & 0.780 & & & & & 0.743 & 0.083 \\
\hline 0.467 & 0.811 & 0.793 & & & & & 0.850 & 0.070 \\
\hline 0.533 & 0.855 & 0.793 & & & & & 0.902 & 0.068 \\
\hline 0.600 & 0.882 & 0.818 & & & & & 0.864 & 0.061 \\
\hline 0.667 & 0.920 & 0.877 & 1.009 & & 1.000 & 0.061 & 0.882 & 0.062 \\
\hline \multirow{2}{*}{$\begin{array}{l}0.733 \\
0.833\end{array}$} & & 0.882 & 0.968 & & 1.093 & 0.054 & & \\
\hline & 0.973 & 0.955 & 1.014 & & 1.084 & 0.055 & 0.991 & 0.055 \\
\hline \multirow{2}{*}{$\begin{array}{l}0.900 \\
1.00 \\
1.067\end{array}$} & & 0.986 & 1.075 & & 1.043 & 0.052 & & \\
\hline & 1.00 & 1.014 & $\begin{array}{l}1.118 \\
1.164\end{array}$ & & 1.114 & $\begin{array}{l}0.047 \\
0.052\end{array}$ & 0.898 & 0.068 \\
\hline \multirow{2}{*}{$\begin{array}{l}.007 \\
1.125 \\
1.167\end{array}$} & & & & 1.114 & & & & \\
\hline & 1.04 & 1.070 & $\begin{array}{l}1.166 \\
1.166\end{array}$ & $\begin{array}{l}1.114 \\
1.109\end{array}$ & $\begin{array}{l}1.166 \\
1.095\end{array}$ & $\begin{array}{l}0.050 \\
0.050\end{array}$ & 1.023 & 0.060 \\
\hline $\begin{array}{l}1.233 \\
1.2333 \\
1.400\end{array}$ & 1.064 & 1.070 & 1.175 & 1.118 & 1.170 & 0.047 & 1.00 & 0.059 \\
\hline \multirow{2}{*}{$\begin{array}{l}1.400 \\
1.500 \\
1.567 \\
1.667 \\
1.833\end{array}$} & 1.080 & 1.123 & 1.170 & $\begin{array}{l}1.141 \\
1.150\end{array}$ & 1.127 & 0.048 & 1.034 & 0.053 \\
\hline & 1.105 & 1.123 & 1.198 & $\begin{array}{l}1.130 \\
1.150\end{array}$ & 1.093 & 0.054 & 1.039 & 0.053 \\
\hline \multirow{7}{*}{$\begin{array}{l}2.000 \\
2.167 \\
2.333 \\
2.667 \\
3.000 \\
3.333 \\
3.667 \\
4.000\end{array}$} & 1.105 & 1.123 & 1.216 & $\begin{array}{l}1.155 \\
1.150\end{array}$ & 1.136 & 0.054 & 1.114 & 0.055 \\
\hline & 1105 & 1118 & 1216 & 150 & 1003 & 0 & 1105 & 0.056 \\
\hline & 1.105 & 1.127 & 1.225 & 1.234 & 1.132 & & 1.118 & 0.045 \\
\hline & 1.100 & 1.150 & 1.220 & 1.189 & 1.132 & 0.046 & 1.105 & 0.041 \\
\hline & 1.105 & 1.150 & 1.216 & 1.184 & 1.136 & 0.046 & 1.166 & 0.045 \\
\hline & 1.100 & 1.150 & 1.216 & 1.184 & 1.136 & 0.048 & 1.123 & 0.049 \\
\hline & & 1.150 & 1.216 & 1.184 & 1.136 & 0.052 & 1.123 & 0.047 \\
\hline
\end{tabular}

(a) The results were obtained with a $r_{0}=7.62 \mathrm{~cm}\left(3.0\right.$ in.) and $U^{\prime}=13.4 \mathrm{~cm} / \mathrm{s}$ $(0.44 \mathrm{ft} / \mathrm{s})$ taken at $z=r_{0}$ upstream and $30.5 \mathrm{~cm}$ (12 in.) from the knoll centerline $(\mathbb{E})$. 


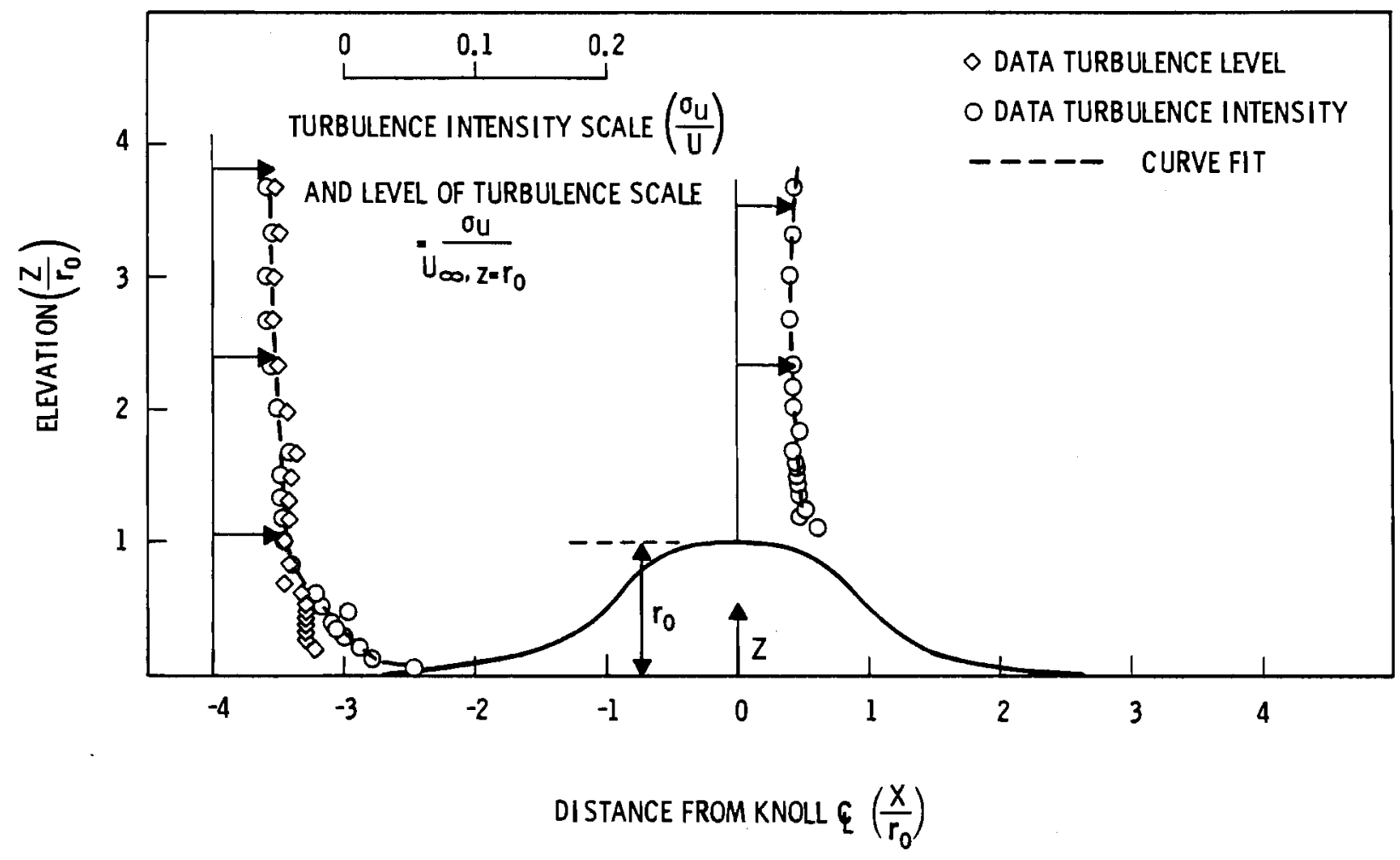

FIGURE 9. Turbulence Intensity Profiles 



\subsection{ERROR AND UNCERTAINTY ANALYSIS}

The results of a detailed error and uncertainty analysis presented in Appendix $B$ indicate that the percent uncertainty associated with mean and rms velocity and turbulence intensity measurements were as follows:

$\%$ uncertainty in mean velocity, - $\pm 10 \%$

$\%$ uncertainty in the level of turbulence, rms, $- \pm 5 \%$

$\%$ uncertainty in the turbulence intensity, - $\pm 11 \%$

The largest contribution to the above percent uncertainties resulted from a stochastic nonstationarity flow condition which may have resulted from insufficient head on the suction side of the pump. 


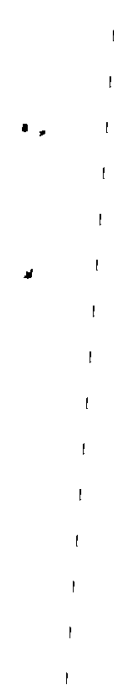




\section{REFERENCES}

1. Taylor, G. I. 1917. Observations and Speculations on the Nature of Turbulent Motion. Reports and Memoranda of the Advisory Committee for Aeronautics, No. 345.

2. Kaufman, J. W., ed. 1977. Terrestrial Environment (Climatic) Criteria Guidelines for Use in Aerospace Vehicle Development, 1977 Revision. National Aeronautics and Space Administration. NASA Technical Memorandum 78118.

3. Counihan, J. 1975. "Adiabatic Atmospheric Boundary Layers: A Review and Analysis of Data from the Period 1880-1972." In Atmospheric Environment, Volume 9, Pergammon Press, New York, pp. 871-905.

4. Engineering Sciences Data Unit. 1974. Characteristics of Atmospheric Turbulence Near the Ground Part II: Single Point Data for Strong Winds (Neutral Atmosphere). Engineering Sciences Data Item No. 74031, London.

5. Cermak, J. E. September 1971. "Laboratory Simulation of the Atmospheric Boundary Layer." AIAA Journal. 9(9):1946-1954.

6. Cermak, J. E. 1974. Applications of Fluid Mechanics to Wind Engineering. A Freeman Scholar Lecture, American Society of Mechanical Engineers, New York.

7. Panofsky, H. A. 1974. "The Atmospheric Boundary Layer Below 150 Meters." In Annual Review of Fluid Mechanics. Volume 6, pp. 147-177.

8. Liu, H. T. and J. T. Lin. May 1976. Plume Dispersion in Stably Stratified Flows Over Complex Terrain, Phase 2. EPA-600/4-76-022, Environmental Sciences Research Laboratory, Office of Research and Development, U.S. Environmental Protection Agency, Research Triangle Park, North Carolina.

9. Hunt, J. C. R, W. H. Snyder, and R. E. Lawson. July 1978. Flow Structure and Turbulent Diffusion Around a Three Dimensional Hi11: Fluid Modeling Study on Effects Stratification Part 1. Flow Structure. EPA-600/4-78-041, Environmental Sciences Research Laboratory, Office of Research and Development, U.S. Environmental Protection Agency, Research Triangle Park, North Carolina.

10. Lin, J. T., H. T. Liu, and Y. H. Poa. February 1974. Laboratory Simulation of Plume Dispersion in Stably Stratified Flows Over Complex Terrain. Flow Research Report No. 29, Flow Research, Inc., Kent, Washington. 
11. Onishi, Y. and D. S. Trent. February 1976. Mathematical and

Experimental Investigations on Dispersion and Recirculation of Plumes From Dry Cooling Towers at Wyodak Power Plant in Wyoming. BNWL-1982, Battelle, Pacific Northwest Laboratory, Richland, Washington.

12. Cliff, W. C. and G. H. Ficht1. July 1978. Wind Velocity-Change (Gust Rise) Criteria for Wind Turbine Design. PNL-2526, Battelle, Pacific Northwest Laboratory, Richland, Washington. 
APPENDIX A

THEORETICAL VELOCITY PROFILE AT THE CREST OF THE KNOLL 
A theoretical mean velocity profile at the crest of a knoll was developed using potential flow theory for flow near a half sphere and a power law approach velocity profile, as follows:

The stream function for potential flow near a sphere of radius $r_{0}$ is given by

$$
\psi=-u_{0} \sin ^{2} \theta\left(\frac{r^{2}}{2}-\frac{r_{0}^{3}}{2 r}\right)
$$

where $U_{0}$ is the freestream velocity.

The velocities $U$ and $U_{r}$ are given by

$$
\begin{aligned}
& U=\frac{1}{r \sin \theta} \frac{\partial \psi}{\partial r}=-U_{0}\left(1+\frac{r_{0}^{3}}{2 r^{3}}\right) \sin \theta \\
& U_{r}=\frac{1}{r^{2} \sin \theta} \frac{\partial \psi}{\partial r}=U_{0}\left(1-\frac{r_{0}^{3}}{r^{3}}\right) \cos \theta
\end{aligned}
$$

where $r$ is the radial distance from the center of the sphere and $\theta$ is the angle subtended from the horizontal.

Directly above the sphere $(\theta=\pi / 2)$, the stream function becomes

$$
\psi_{\theta=\pi / 2}=-U_{0}\left(\frac{r^{2}}{2}-\frac{r_{0}^{3}}{2 r}\right)
$$


or

$$
\frac{\Psi_{\theta=\pi / 2}}{-U_{0}}=\left(\frac{r^{2}}{2}-\frac{r_{0}^{3}}{2 r}\right)
$$

The left side of Equation A.4 may be thought of as a function of the square of the upstream (us) height of a stream line that passes over the crest of the hill at the height $r$ with a velocity equal to

$$
U=F\left[U_{U S}\left(1+\frac{r_{0}^{3}}{2 r^{3}}\right)\right]
$$

The upstream height corresponding to a given stream function would be

$$
z_{u s}=\left(\frac{\psi_{\theta=\pi / 2}}{-U_{0}}\right)^{1 / 2}=\left(\frac{r^{2}}{2}-\frac{r_{0}^{3}}{2 r}\right)^{1 / 2}
$$

Thus, for a power law velocity profile upstream, the velocity at height $Z$ may be expressed as

$$
\frac{U_{Z}}{U_{Z=r_{0}}}=\left(\frac{Z}{r_{0}}\right)^{n}
$$

The velocity profile at the crest of the hill would be

$$
U=F\left[U_{u s, Z=r_{0}}\left(1+\frac{r_{0}^{3}}{2 r^{3}}\right)\right]\left[\frac{r^{3}-r_{0}^{3}}{2 r r_{0}^{2}}\right]^{n / 2}
$$


or

$$
U=U_{u s, Z=r_{0}}\left[\frac{1}{2}\left(x^{2}-\frac{1}{x}\right)\right]^{n / 2}\left(1+\frac{1}{2 x^{3}}\right) f(n)
$$

where $x=\frac{r}{r_{0}}$ and $f(n)$, which is a function of the velocity power law exponent, forces the stream lines at large distances from the model knoll to be unaffected by the knoll. Taking the limit as $X$ approaches infinity of the ratio of the velocity at the crest of the knoll to the upstream velocity yields

$$
\begin{aligned}
\operatorname{limit}_{X \rightarrow \infty} \frac{U_{\text {crest }}}{U_{u s}} & =\frac{U_{u s, Z=r_{0}}\left[\frac{1}{2}\left(x^{2}-\frac{1}{x}\right)\right]^{n / 2}\left(1+\frac{1}{2 x^{3}}\right) f(n)}{U_{Z=r_{0}}(x)^{n}} \\
& =1=\left(\frac{1}{2}\right)^{n / 2} f(n) \Rightarrow f(n)=2^{n / 2}
\end{aligned}
$$

Equation A.7 for the velocity profile over the crest of the knoll now becomes

$$
U_{\text {crest }}=U_{\text {us, } Z=r_{0}}\left(x^{2}-\frac{1}{x}\right)^{n / 2}\left(1+\frac{1}{2 x^{3}}\right)
$$




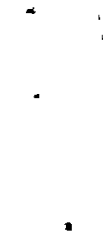


APPENDIX B

ERROR AND UNCERTAINTY ANALYSIS 
APPENDIX B

ERROR AND UNCERTAINTY ANALYSIS

The purpose of this appendix is to present estimates of the accuracy of the measured values of mean velocities, turbulent velocities and turbulence intensities obtained using the laser Doppler system. Uncertainties exist in each variable encountered while taking a velocity measurement. These variables include the wavelength of the laser beam, the size and location of the sample volume, the diameter of the laser beam, the diameter of the optics, the angle subtended between the two laser beams, the calibration of the frequency to velocity electronics, and the ability and accuracy with which a value is read by the operator or data acquisition system as well as a host of other factors.

The velocity reported may be expressed as a function of these variables as

$$
u=f\left(x_{1}, x_{2}, x_{3}, \ldots x_{n}\right)
$$

Using the chain rule for differentiation, the total differential of the velocity may be expressed as

$$
d U=\frac{\partial U}{\partial x_{1}} d x_{1}+\frac{\partial U}{\partial x_{2}} d x_{2}+\ldots \frac{\partial U}{\partial x_{n}} d x_{n}
$$

If each of the variables is independent of one another, the variance of the velocity may be expressed as

$$
\begin{aligned}
\left\langle(d u)^{2}\right\rangle= & \left\langle\left(\frac{\partial u}{\partial x_{1}}\right)^{2}\left(d x_{1}\right)^{2}\right\rangle+\left\langle\left(\frac{\partial u}{\partial x_{2}}\right)^{2}\left(d x_{2}\right)^{2}\right\rangle+\ldots \\
& \left\langle\left(\frac{\partial u}{\partial x_{n}}\right)^{2}\left(d x_{n}\right)^{2}\right\rangle
\end{aligned}
$$


where $\left\langle(A)^{2}\right\rangle$ is the variance of $(A)$ taken over an ensemble of realizations. Since both sides of the above equation can be multiplied by any desired constant, it follows that each term can be equated to any desired number of standard deviations of the individual variable. Thus, the uncertainty of the velocity may be written as:

$$
w_{U}=\left(\left(\frac{\partial U}{\partial X_{1}}\right)^{2} w_{X_{1}}^{2}+\ldots\left(\frac{\partial U}{\partial X_{n}}\right)^{2} w_{X_{n}}^{2}\right)^{1 / 2}
$$

where $W_{U}$ and $W_{X}$ are the uncertainties in the measurements of $U$ and $X_{n}$ within a desired confidence level (unless otherwise stated, a confidence level of $95 \%$ was used throughout this uncertainty analysis). This means that 19 out of 20 samples will fall within the value indicated by $W_{U}$ and $W_{X_{n}}$. The percent uncertainty is calculated by dividing the uncertainty by the nominal value of the variable. That is

$$
\% \text { uncertainty }= \pm \frac{W_{U}}{U}
$$

Since the uncertainty in the velocity $U$ is a function of the square root of the sum of the squares of the uncertainties of the variables, only variables which may have large uncertainties need be considered.

Aside from human errors, the uncertainty in the measured velocity will be considered to be a function only of the wavelength of the laser, $\lambda$, the angle subtended by the two converging laser beams, $\theta$, and the measured frequency of the Doppler signal, $f$.

$$
\begin{aligned}
& \text { Since } U=\frac{\lambda f}{\sin \theta / 2} \text { where } U=0.134 \mathrm{~m} / \mathrm{s} \\
& \lambda=0.5145 \times 10^{-6} \mathrm{~m} \\
& \theta=0.043574 \text { radians }
\end{aligned}
$$




$$
\begin{aligned}
& f=25,000 \mathrm{~Hz} \\
& \Delta \lambda \simeq 0.001 \times 10^{-6} \mathrm{~m} \\
& \Delta \theta \simeq 0.002 \text { radians } \\
& \Delta f \simeq 100 \mathrm{~Hz} \\
& \% \text { error }=100\left(\frac{W_{U}}{U}\right)=\frac{100}{U}\left[\left(\frac{f}{\sin \theta / 2}\right)^{2} W_{\lambda}^{2}+\left(\frac{\lambda}{\sin \theta / 2}\right)^{2} W_{f}^{2}\right. \\
&\left.+\left(\frac{\lambda_{f} \cos \frac{\theta}{2}}{z \sin ^{2} \frac{\theta}{2}}\right)^{2} W_{\theta}^{2}\right] 1 / 2 \\
&=\frac{100}{0.59\left[(0.0011)^{2}+(0.0024)^{2}+(0.0006)^{2}\right] 1 / 2} \\
& \% \text { uncertainty of } U=100\left(\frac{0.0027}{0.59}\right)=0.46 \%
\end{aligned}
$$

The percent uncertainty in the measured velocity contributed by $\lambda, f$, and $\theta$ were $0.19 \%$, $0.41 \%$, and $0.10 \%$, respectively.

The error analysis indicates that the measurement of velocity is extremely accurate. However, there was a greater uncertainty associated with the reported mean velocity because at times the flowrate in the flume appeared to fluctuate. This fluctuation may have resulted from insufficient head on the suction side of the pump. The instantaneous velocities measured during these fluctuations, although extremely accurate, does represent a stochastic nonstationary (transient) flow condition which was being used to approximate a stochastic stationary (steady-state) flow. Instantaneous values of velocity not due to turbulence departed from the stationary case by as much as $20 \%$. Time averaging, however, reduces this departure from the stationary case to within $5 \%$ to $10 \%$. This departure from stationary flow was significantly greater than the uncertainty associated with the measurement; therefore, the 
fluctuations in the flow were the uncertainty that governed the overall uncertainty of the mean velocity measurement. Thus, the expected uncertainty of the mean velocity measurement was

$$
\% \text { uncertainty in mean velocity } \simeq \pm 10 \%
$$

The uncertainty in the level of turbulence was not as great as the uncertainty in the mean velocity due to an analog time averaging of the true rms meter with which the data was taken. Thus, the expected uncertainty in the level of turbulence was

$$
\% \text { uncertainty in the level of turbulence } \simeq \pm 5 \%
$$

The turbulence intensity is defined as

$$
T_{i}=\text { turbulence intensity }=\frac{\sigma_{u}}{U}
$$

The $\%$ uncertainty in the turbulence intensity value is $\pm 11 \%$. 


\section{DISTRIBUTION}

No. of

Copies

\section{OFFSITE}

A. A. Churm

DOE Chicago Patent Dvision

9800 South Cass Avenue

Argonne, IL 60439

Alan Rubin

Room J 413

Energy Technology

U.S. Department of Energy Washington, DC 20545

27 DOE Technical Information Center

ONSITE

DOE Richland Operations Office

H. E. Ransom
No. of

Copies

85 Pacific Northwest Laboratory

W. C. Cliff (70)

J. M. Creer

W. W. Laity (2)

J. D. Smith (4)

A. M. Sutey

Technical Information (5)

Publishing Coordination KE(2) 
